\title{
Amino covalent binding approach on iron oxide nanoparticle sur- face: toward biological applications
}

\author{
Nébéwia Griffete ${ }^{1,2}$, Martin J. D. Clift ${ }^{1}$, Aazdine Lamouri ${ }^{3}$, Reinaldo G. Digigow ${ }^{1}$, Adriana M. Mihut ${ }^{1}$, \\ Alke Fink $^{1,4}$, Barbara Rothen-Rutishauser ${ }^{1,5}$ and Hervé Dietsch ${ }^{1 * \dagger}$ \\ ${ }^{1}$ Adolphe Merkle Institute and Fribourg Center for Nanomaterials, University of Fribourg, Route de l'Ancienne Papeterie \\ P.O. Box 209, 1723 Marly 1, Switzerland \\ ${ }^{2}$ Department of Physics and Fribourg Center for Nanomaterials, University of Fribourg, Chemin du Musée 3, 1700 Fribourg, \\ Switzerland \\ ${ }^{3}$ Univ. Paris Diderot, Sorbonne Paris Cite, ITODYS, UMR 7086 CNRS, 15 rue J-A de Baif, 75205 Paris Cedex 13, France. \\ ${ }^{4}$ Department of Chemistry and Fribourg Center for Nanomaterials, University of Fribourg, Chemin du Musée 9, 1700 Fri- \\ bourg, Switzerland \\ ${ }^{5}$ Respiratory Medicine, Bern University Hospital, Inselspital, Freiburgstrasse, CH-3010 Bern, Switzerland
}

Corresponding Author: herve.dietsch@unifr.ch

Present Addresses

†BASF SE, Formulation Platform, 67098 Ludwigshafen am Rhein, Germany. E-mail: herve.dietsch@basf.com

KEYWORDS. Iron oxide nanoparticles, surface modification, diazonium salts, biological applications

\begin{abstract}
We report on the synthesis and the surface modification of different types of magnetic iron oxide particles by developing an original process based on diazonium salts chemistry. Particles were first coated with amino groups and then subjected to polyethylene glycol (PEG) surface modification. They were subsequently characterized by Transmission electron microscopy, infrared spectroscopy, diffraction light scattering and by Zeta potential. To show the efficiency of this surface modification method, the potential cytotoxicity and (pro-)inflammatory effect of the PEG magnetic particles were also analyzed in vitro. This covalently surface modification approach based on diazonium salts chemistry provides individually dispersed, PEG-modified magnetic nanoparticles suitable for biological applications.
\end{abstract}

\section{Introduction}

Functionalized magnetic nanoparticles (NPs) have been intensively investigated in recent years. Amongst other applications upon their potential biomedical applications ${ }^{1-6}$, many are used as carriers for the cellular delivery of various drugs ${ }^{7,8}$. However, to meet the requirements for cellular delivery, iron oxide nanoparticles (IONPs) have to be subjected to chemical modification, such as strong affinity between the carriers and biomolecules, as well as a good biocompatibility, amongst others, for example to allow for targeting or to enhance circulation times. Surface modification of these NPs can improve the interaction between NPs and biomolecules ${ }^{9,10}$. Modified NPs as carriers for drugs and biomolecules have several advantages, such as the grafting of specific biomolecules onto NPs able to provide site specific delivery into cells ${ }^{11}$.
The use of NPs in vivo is limited by many of their characteristics when present within biological fluids, such as their agglomeration status which can be induced by their high surface energies and tendency to adsorb proteins ${ }^{12}$. The addition of a polymer layer to the surface of IONPs, can stabilize these NPs and allow for a well-dispersed individual nanoparticle sample placed in biological fluids for both in vitro and in vivo applications ${ }^{13,14}$. Moreover, the polymer layer can endow IONPs with a functionality for the encapsulation or attachment of therapeutic agents ${ }^{15,16}$.

Encapsulation of iron oxide nanoparticles into polymers is an original process to obtain biocompatible hybrid materials for controlled drug delivery systems ${ }^{17}$ or in cellular application $^{18}$. One of the most commonly used surface modification techniques is the attachment of silane compounds. This involves the use of many functional silanes, like alcohol and amines, that are useful for NP biofunctio- 
nalization ${ }^{19,20}$. Phosphonic acid ${ }^{21}$ and carboxylic groups $s^{22}$ also show a strong affinity for IONPs surfaces by interacting with the surface with a co-ordination process. Dopamine $^{23}$ is also important in the attachment of a range of biologically molecules (e.g. peptides) to IONPs. This process has shown limitations in term of suspensions stability of IONPs in water and biological fluids after chronic exposure $^{24}$. By using such chelate type anchoring groups, their binding to metal oxide surfaces often fails in aqueous or protic media due to the hydrolytic instability of the surface attachment. Therefore, the development of versatile and efficient surface modification strategies for obtaining strong and stable linkages in aqueous media, between the IONPs surface and the polymer coating still remains a significant challenge.

An original method to modify covalently iron oxide surfaces by using diazonium salts chemistry has previously been reported by Griffete et al. ${ }^{25-27}$ This strategy has enabled a monolayer of functional aryl groups to be covalently grafted to the surface of the IONPs. In basic media, the diazonium group of the molecule is first transformed into diazohydroxide, an intermediate form. The diazohydroxide is deprotonated with the alkaline $\mathrm{pH}$ and it forms an unstable diazoate group that causes the molecule to become an aminophenyl radical. If these radicals are present during the synthesis of $\mathrm{Fe}_{3} \mathrm{O}_{4} \mathrm{NPs}$, these aryl radicals form NPs modified with aryl groups through covalent linkages affording to a highly stable anchoring of the organic coating at the surface of the NPs. Diazonium salts have been widely used as coupling agents for the grafting of polymer coatings upon carbon-based ${ }^{28}$ and metallic ${ }^{29}$ (platinum, ruthenium, palladium, gold and titanium) planar and/or NP surfaces, affording strong linkages.

Here we report a very simple RT aqueous synthesis procedure, yielding iron oxide NPs with a covalent attachment dispersible in almost any solvent, and especially in water. To this end, we took the advantage of the potential of the grafting of aryl groups derived diazonium salts onto the surface of IONPS. The amine coordinating group attachment to the IONPs surface was motivated by the observation that amino groups lead to well defined IONPs. Primary amines were selected since amine coupling procedures can be used to conjugate with a large variety of proteins, peptides, or other biologically relevant molecules. In addition, understanding the biological interaction of these IONPs was also realised by investigating their ability to cause a cytotoxic and (pro-)inflammogenic response to epithelial barrier cells in vitro. As a proof of concept, commercial polyethylene glycol (NHS PEG), commonly used for protein or dyes attachment ${ }^{30}$, were attached to amino groups covalently fixed on the surface of the IONPs. Three different types of IONPs (magnetite spherical nanoparticles labelled $\mathrm{Fe}_{3} \mathrm{O}_{4} \mathrm{NP}$, spindle and cubic hematite nanoparticles labelled SHt and CHt respectively) were modified in order to highlight the increased versatility of this method. Figure 1 presents the strategy used for IONPs surface functionalization.

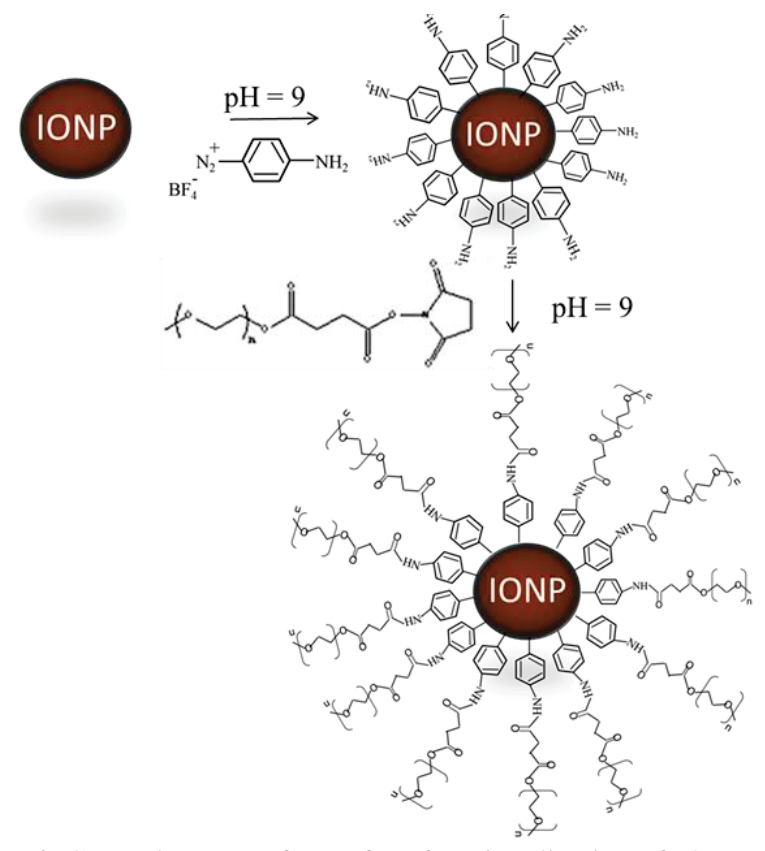

Fig. 1. General strategy for surface functionalization of IONPs.

To characterize the final products of amino coated oxide nanoparticles and pegylated coated oxide nanoparticles different methods can be used ${ }^{31}$ and we decided to fully characterized them by IR, Zeta potential, DLS and TEM.

\section{Experimental}

\subsection{Materials}

$\mathrm{FeCl}_{3} \cdot 6 \mathrm{H}_{2} \mathrm{O}, \mathrm{FeSO}_{4} \cdot 7 \mathrm{H}_{2} \mathrm{O}, \mathrm{NaOH}$, paraphenylenediamine and concentrated $\mathrm{HCl}$ was purchased from Sigma Aldrich. Commercial PEG (Sunbright MA-050TS) was purchased from NOF America Corporation. For all cell experiments, chemicals and reagents were purchased from Sigma-Aldrich, Switzerland, unless otherwise specified.

\subsection{Characterization}

Infrared spectroscopy was performed upon dried samples with a FT-IR Spectrometer Tensor 27 from Bruker equipped with a golden gate. Transmission electron microscopy (TEM-CM100, Philips) operating at $80 \mathrm{keV}$ was used to determine the size and morphology of the synthesized particles. Samples for TEM were prepared by drying one droplet of 0.5 vol \% of IONPs onto a carbon-coated (300 mesh) grid. The electrophoretic mobility of the particles was determined at $25^{\circ} \mathrm{C}$ using a 90Plus Particle Size Analyser from Brookhaven Instruments. The results shown represent an average from at least ten individual measurements. The $\mathrm{pH}$ dependence was investigated in dilute suspensions $(0.02 \mathrm{~g} / \mathrm{L})$ and the $\mathrm{pH}$ was adjusted by $\mathrm{NaOH}$ or $\mathrm{HCl}(0.1 \mathrm{M})$. The same suspensions were used for the dynamic light scattering (DLS) measurements, the same suspensions were used. The hydrodynamic radii of IONPs were determined at different scattering angles (from $45^{\circ}$ to $130^{\circ}$ ) at $25^{\circ} \mathrm{C}$, on a Goniometer System from LS Instruments AG (Fribourg, Switzerland) equipped with a HeNeLaser operating at a wavelength of $632.8 \mathrm{~nm}$. The resulting 
apparent hydrodynamic radius was evaluated from first cumulant analysis via the Stokes-Einstein relation.

\subsection{Preparation of the materials}

Synthesis of the diazonium salt $\mathrm{Cl}-,+\mathrm{N}_{2}-\mathrm{C}_{6}-\mathrm{H}_{4}-\mathrm{NH}_{2}$. To $3.71 \mathrm{~g}(17 \mathrm{mmol})$ of phenylenediamine, cooled at $0^{\circ} \mathrm{C}$ in an ice bath, $10 \mathrm{ml}$ of concentrated hydrochloric acid $(\mathrm{HCl})$ was added dropwise under continuous vigorous stirring. A total of $2.35 \mathrm{~g}(34 \mathrm{mmol})$ of sodium nitrite $\left(\mathrm{NaNO}_{2}\right)$ was added and the reaction was then left to proceed for $10 \mathrm{~min}$. The subsequent solution was then subjected to lyophilization to extract the water in order to isolate the diazonium salt powder. The powder was dried and stored at $-5^{\circ} \mathrm{C}$. IR : $\mathrm{N}_{2}^{+}$at $2155 \mathrm{~cm}^{-1}$. 1H NMR (400 MHz, DMSO), ppm: 8.28 (d, 2H, J=7.3 Hz), 7.07 (d, 2H, J=7.3 Hz), $4.23(\mathrm{~S}, 1 \mathrm{H})$ and $3.26(\mathrm{~S}, 6 \mathrm{H})$. (Further information available supporting information S1). Caution! in general diazonium salts in the dry state are potentially explosive. Therefore they must be carefully stored and handled.

Synthesis of the IONPs. Magnetite nanoparticles were synthesized as follows: In a typical reaction, $2.9 \mathrm{mmol}$ of $\mathrm{FeCl}_{3}$ and $1.2 \mathrm{mmol}$ of $\mathrm{FeSO}_{4}$ were dissolved in $5 \mathrm{~mL}$ of deionized water. The solution was purged with nitrogen, and the inert atmosphere was maintained for the duration of the synthesis. Then $3 \mathrm{~mL}$ of $\mathrm{NaOH}(\mathrm{c}=1 \mathrm{M})$ were rapidly added under vigorous stirring. The colour of the solution changed immediately from yellow to dark, indicating the formation of $\mathrm{Fe}_{3} \mathrm{O}_{4}$ nanoparticles. Following the incubation period, the particles were washed three times with water. Anisotropic spindle hematite nanoparticles were synthesized based on the method described by Ocaña et $\mathrm{al}^{32}$. In a typical synthesis, a $2 \mathrm{~L}$ glass bottle was loaded with $92.4 \mathrm{~g}$ of $\mathrm{Fe}\left(\mathrm{ClO}_{4}\right)_{3}, 6 \mathrm{H}_{2} \mathrm{O}(200 \mathrm{mmol}), 1.3 \mathrm{~g}$ of $\mathrm{NaH}_{2} \mathrm{PO}_{4}, 3 \mathrm{H}_{2} \mathrm{O}$ $(9.4 \mathrm{mmol})$, and $12 \mathrm{~g}$ of urea $\left(\mathrm{NH}_{2}\right)_{2} \mathrm{CO}(0.2 \mathrm{~mol})$ in $2 \mathrm{~L}$ of ultra-pure water and then sonicated until a homogeneous solution resulted. The solution was kept in a preheated oven at $98^{\circ} \mathrm{C}$ for $24 \mathrm{~h}$. The supernatant was then decanted and the precipitate was cleaned by seven successive cycles of washing with pure water and centrifugation at 13000 rpm for 10 min to remove any impurities. Cubic hematite NPs were synthesized as follows: a 1 L glass bottle was charged with $2.45 \mathrm{~g}$ of $\mathrm{FeCl}_{3}, 6 \mathrm{H}_{2} \mathrm{O}$ in $1 \mathrm{~L}$ of ultra-pure water. The solution was kept at $97^{\circ} \mathrm{C}$ for 7 days. The solution was cleaned by seven successive cycles of washing with pure water and centrifugation at $13000 \mathrm{rpm}$ for 10 min to remove the impurities

Amino covalent grafting. In a typical grafting experiment, particles $(100 \mathrm{mg})$ were dispersed in a basic aqueous solution $([\mathrm{NaOH}]=0.1 \mathrm{M})$ in to which the diazonium salt $(0.5$ $\mathrm{mM}$ ) was added. After $20 \mathrm{~min}$ the particles were washed and dried.

Pegylation. For the pegylation, $50 \mathrm{mg}$ of particles were dispersed in a basic aqueous media $(\mathrm{pH} \mathrm{9})$ and $10 \mathrm{mg}$ of NHS-PEG was added to the solution under vigorous stirring over a $6 \mathrm{~h}$ period. The particles were then washed and dried for subsequent analysis.
Cell Culture. The human alveolar type-II epithelial cell-line A549, obtained from the ACCC, was cultured as a monolayer on micro-porous membrane inserts in a 6 well-plate at a density of $0.5 \times 10^{6}$ cells $\mathrm{ml}^{-1}$. Cells were cultured in Rosewell Park Memorial Institute cell culture media containing supplements of $10 \%$ foetal bovine serum, $1 \% \mathrm{~L}$ Glutamine and $1 \%$ Pennicillin/Streptomycin (hereafter referred to as 'cell culture medium') at $37^{\circ} \mathrm{C}, 5 \% \mathrm{CO}_{2}$ for 5 days prior to $\mathrm{Fe}_{3} \mathrm{O}_{4} \mathrm{NP}$ exposure.

NP Preparation and Exposure. Both $\mathrm{Fe}_{3} \mathrm{O}_{4}$ NPs with and without PEG coating were prepared from their $0.1 \mathrm{mg} \cdot \mathrm{ml}^{-1}$ stock solutions in $\mathrm{H}_{2} \mathrm{O}$ to particle concentrations of 0.01 , $0.02,0.04$ and $0.08 \mathrm{mg}_{\mathrm{ml}} \mathrm{m}^{-1}$ in cell culture medium. Both the stock solutions and working particle concentrations were vigorously vortexed prior to use. The concentrated NP samples were then exposed to the A549 epithelial cell cultures via the suspension method (submerged cultures) and incubated at $37^{\circ} \mathrm{C}, 5 \% \mathrm{CO}_{2}$ for 24 hours. Following the exposure period, cell supernatants were collected for subsequent biochemical analysis.

\subsection{Biochemical Analysis.}

Cell supernatants collected from the exposed A549 cell cultures were assessed for total release of the cytosolic enzyme lactate dehydrogenase (LDH) as a measure of the different NPs ability to cause cytotoxicity, as well as the release of the (pro-)inflammatory chemokine interleukin-8 (IL-8). For both biochemical assays, cell culture medium acted as the negative control. The solvent Triton X100 was used at $0.2 \%$ in PBS as the positive control for $\mathrm{LDH}$ release, whilst the cytokine tumour necrosis factor (TNF) performed as the positive control at $0.1 \mathrm{mg} \cdot \mathrm{ml}^{-1}$ for IL-8 release. Each method was repeated three times $(n=3)$, on separate occasions and different cell cultures in triplicate. Determination of the extent of cell membrane permeability following NP exposure, thus allowing LDH to be released into the cell supernatant, was assessed using a LDH diagnostic kit, as per the manufacturer's instructions (Roche Applied Sciences, Switzerland). Investigation into the ability for the NPs to elicit IL-8 release, indicating an intracellular inflammatory response caused by the NPs, was measured using an enzyme-linked immunosorbant (ELISA) diagnostic kit, as per the manufacturer's instructions (DuoSet ELISA diagnostic kit, R\&D Systems, Switzerland).

Statistical Analysis. All biological data sets were found to be normally distributed (data not shown). Therefore, a twoway analysis of variance (ANOVA) was performed with a Tukey's Post hoc test (SPSS, IBM, USA). Statistical significance was assumed when $\mathrm{p} \leq 0.05$.

\section{Results and discussion}

IONPs (spindle and cubic hematites, spherical magnetite NPs) were synthesized in aqueous suspension. The particles were subsequently coated with amino groups in basic solution and were characterized by TEM and infrared spectroscopy (IR). 


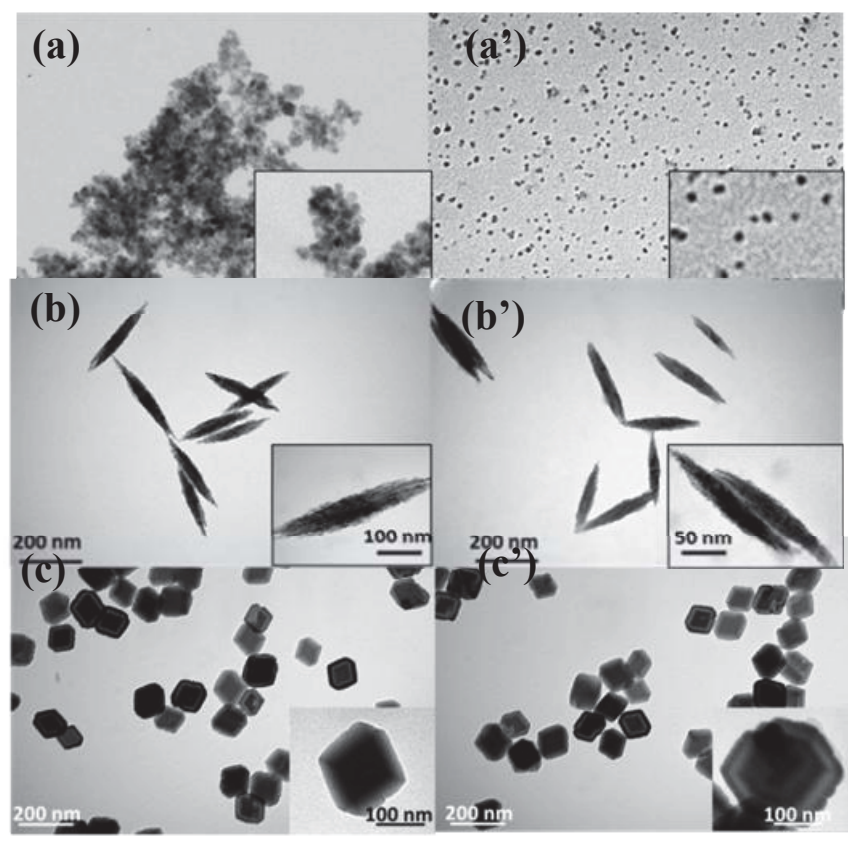

Fig. 2. Transmission electron micrographs showing bare spherical magnetite nanoparticles (a), bare spindle hematites (b), bare cubic hematites (c) and their coating with PEG respectively (a'), (b'), (c').

TEM show that the three different types of IONPs are mostly uniform in size (Fig. 2). Although the PEG layer is not visible using electron microscopy around the IONPs, the dispersion was improved after the functionalization of their surface with PEG especially for magnetite spherical nanoparticles (Fig 2a'), indicating the presence of polymer groups around each iron oxide NPs. DLS and zeta potential confirmed the presence of a polymer layer and will be discussed later.

IR spectroscopy was subsequently performed investigate the presence of amines and PEG on the NPs surface. Figure 3 shows the infra-red spectrum from 500 to $4000 \mathrm{~cm}^{-1}$ of the bare magnetite NPs, the amino coating and the pegylated IONPs. The infra-red spectra obtained for cubic hematites and spindle-type hematites NPs are presented in the supporting information (Figure S2).

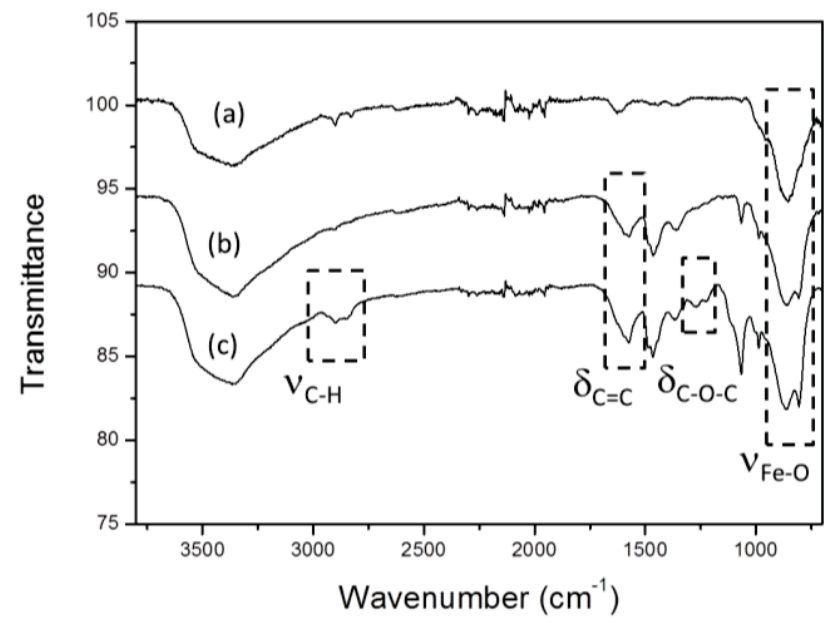

Fig. 3. FT-IR spectra of (a) $\mathrm{Fe}_{3} \mathrm{O}_{4}$ NPs (b) amino coating $\mathrm{Fe}_{3} \mathrm{O}_{4}$ NPs (labeled $\mathrm{Fe}_{3} \mathrm{O}_{4} @ \mathrm{NH}_{2}$ ) and (c) pegylated $\mathrm{Fe}_{3} \mathrm{O}_{4}$ NPs (labeled $\left.\mathrm{Fe}_{3} \mathrm{O}_{4} @ \mathrm{NH}_{2} @ \mathrm{PEG}\right)$.

The IR spectra of IONPs exhibit strong bands in the low frequency region $\left(1000-400 \mathrm{~cm}^{-1}\right)$ due to the iron oxide skeleton. In other regions, the spectrum of iron oxide show only weak bands. The IR spectrum of $\mathrm{NP}-\mathrm{C}_{6} \mathrm{H}_{4}-\mathrm{NH}_{2}$ shows the appearance of one main intensive band at 1570 $\mathrm{cm}^{-1}$ due to the phenyl $\delta_{\mathrm{C}=\mathrm{C}}$ vibrations. It is noteworthy that the $\mathrm{N}=\mathrm{N}$ stretching mode near $2280 \mathrm{~cm}^{-1}$ appearing in the IR spectrum (see figure S3 in supporting information) of the free diazonium salts is not visible in the spectra of the functionalized NPs, indicating the release of $\mathrm{N}_{2}$ as a consequence of the cleavage of the diazonium moieties during the grafting process. Modifications appear in the spectrum of IONP-PEG: the C-O-C ether stretch band at $1106 \mathrm{~cm}^{-1}$ and the vibration band at $1344 \mathrm{~cm}^{-1}$ (antisymmetric stretch) appear in the IR spectrum of the nanoparticles after PEG modification. Similarly, the bands around 2912 and 955 $\mathrm{cm}^{-1}$ correspond to $-\mathrm{CH}$ stretching vibrations and $-\mathrm{CH}$ outof-plane bending vibrations, respectively. The C-O-C and $\mathrm{CH}$ peaks elicit further heightened evidence towards the fact that PEG covered the NPs surface. Unfortunately, it is impossible to discriminate the chemical grafting of HNSPEG by using the Infra-red technique. Indeed, the amino functionalized iron oxide NPs show bands in the high frequency (around $3400 \mathrm{~cm}^{-1}$ ) near the hydroxyl groups frequency that are present because of the iron oxide NPs. To confirm the presence of amine groups on the surface of iron oxide NPs, elemental analysis of nitrogen was first performed. The total percent of nitrogen present in the sample is $0.02 \%$ and by correlating with the amount of particles present in the sample, we found $2.2 \mathrm{mg} / \mathrm{g}$ (mg of amino function/g of particles). (See Supporting information for the calculation).To provide further evidence of the presence of amino groups on the surface of the iron oxide NPs, different method can also be used $^{33}$. For this, the Hermanson's method was used (please refer to supplementary information). This method is a colorimetric method $^{34}$ based on the complexation of the free amino group with TNBSA that forms a yellow colour. The measurement of the colour intensity by spectroscopic methods allows the determination of the concentration with a calibration curve. This method gave an approximate concentration of amino groups of $68 \mu \mathrm{g} / \mathrm{mL}$ of sample. This concentration was correlated to the mass of bare particles present in $1 \mathrm{~mL}$ of solution and $(0.059 \mathrm{~g}$ of bare particles in $1 \mathrm{~mL}$ of solution) conducting to a concentration $1.2 \mathrm{mg} / \mathrm{g}$ ( $\mathrm{mg}$ of amino function/g of particles). The obtained results from the two different methods to calculate the concentration of the amine groups are comparable and confirm the effective presence of the amino groups on the surface of iron oxide.

The zeta potential measurements can provide information concerning the chemical grafting of the PEG onto the surface of iron oxide NPs. Particle stability, hydrodynamic radius and the electrophoretic mobility were determined as a function of $\mathrm{pH}$ for the three different IONPs with a particle concentration of $0.02 \mathrm{~g} / \mathrm{L}$ at $25^{\circ} \mathrm{C}$ (Figure 4). As shown in previous works ${ }^{35}$, the isoelectric point of bare 
hematite NPs, on the basis of zeta potential measurements, is between 7 and 8 . At $\mathrm{pH}$ values above or below $\mathrm{pH} 7$ and 8 , respectively, the particles are stabilized by electrostatic repulsions. A similar result was observed for magnetite $\mathrm{NPs}^{36}$. After surface modification of the hematite and magnetite NPs with amino groups, the isoelectric point increased to $\mathrm{pH} 10$, i.e. the $\mathrm{pKa}$ value of amino groups as presented in figure $4 \mathrm{a}$. This increase confirms the effective presence of amino groups on the surface of IONPs. At this $\mathrm{pH}$ value, the particles are stabilized by electrostatic repulsions and as expected, the apparent hydrodynamic radius measured by DLS is similar for environments at a $\mathrm{pH}$ below 10 (see figure 4c). Above this value, the Zeta potential is negative due to the presence of the hydroxyl groups that are deprotonated, but the surface of the iron oxide NPs are still uncharged and this led to the precipitation of the particles as evidenced by the hydrodynamic particle size presented in figure 4c. It is to note that the hydrodynamic radii obtained for amino functionalized magnetite NPs is above $70 \mathrm{~nm}\left(\mathrm{D}_{\mathrm{TEM}}=10 \mathrm{~nm}\right)$ even in basic $\mathrm{pH}$ and can be attributed to the presence of some iron oxide nanoparticles clusters.

After pegylation, the zeta potential was found to be 0 over the entire $\mathrm{pH}$ range, which shows that most surface amino groups were now linked to PEG (see figure $4 \mathrm{~b}$ ). The polymer surface coating influence the aggregation behavior as the NPs are not stabilized by electrostatic repulsion after pegylation. The hydrodynamic radii remained unchanged even at very basic $\mathrm{pH}$ values as shown in figure $4 \mathrm{~d}$. On the other hand, the hydrodynamic radii increase dramatically after pegylation compared to IONPs coated with amino groups at $\mathrm{pH} 7$. For example, the $\mathrm{R}_{\mathrm{h}}$ obtained at $\mathrm{pH} 7$ for $\mathrm{SHt} @ \mathrm{NH}_{2}$ is $72 \mathrm{~nm}$ and after pegylation is $130 \mathrm{~nm}$, for $\mathrm{CHt} @ \mathrm{NH}_{2}$ is $87 \mathrm{~nm}$ and after pegylation is $139 \mathrm{~nm}$. Thus, the increase in the hydrodynamic radii confirms the reaction between the amino groups coated to the surface with the $\mathrm{SH}$ groups from the commercial PEG.
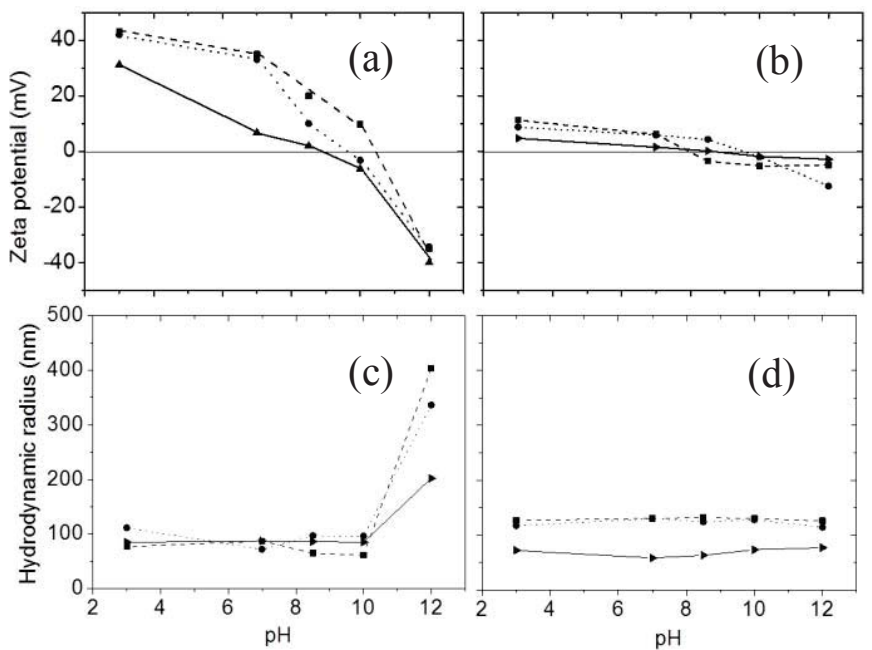

Fig. 4. Zeta potential (a and b) and corresponding hydrodynamic radii (c and d) for magnetite (solid line), spindle hematites (dashed line), cubic hematites (dotted line). (a) and (c) correspond to the amino-coated IONPs and (b) and (d) correspond to the pegylated particles.

However, $\mathrm{R}_{\mathrm{h}}$ obtained for $\mathrm{Fe}_{3} \mathrm{O}_{4} @ \mathrm{NH}_{2}$ (74 nm) are higher compared to $\mathrm{Fe}_{3} \mathrm{O}_{4} @ \mathrm{NH}_{2} @$ PEG (43 nm) at pH 7. This phenomenon can be explained by the size of the linker which is now attached to the particle surface which is too small in the first case to stabilize the IONPs, and the electrostatic stabilization is simply not sufficient. Steric stabilization allows increasing stability of the $\mathrm{Fe}_{3} \mathrm{O}_{4} \mathrm{NPs}$.

This study clearly shows considerable improvements in the particle stability due to the use of ionizable groups on the IONPs surface. Our innovative process for the surface coating of IONPs allows working under conditions which approach the $\mathrm{pH}$ values encountered in biological applications.

To quantify the organic coating of the produced NPs, thermal gravimetric analyses were performed in the temperature range of $30-600^{\circ} \mathrm{C}$ with a heating rate of $10^{\circ} \mathrm{C} / \mathrm{min}$ (Fig. 5). The observed total weight loss was assumed to be due to the desorption and/or decomposition of the organic coating shell. A total weight loss of $13 \%$ was observed upon heating $\mathrm{NP}-\mathrm{C}_{6} \mathrm{H}_{4}-\mathrm{NH}_{2}$ to $600{ }^{\circ} \mathrm{C}$ as seen in figure $5 \mathrm{~b}$ while the uncoated NPs showed a weight loss of only $4 \%$ (probably due the possible existence of hydroxide groups at the NPs surface and to some contamination)(figure 5a). This result suggests a high grafting density of the amino groups on the surface of the NPs.

Taking into account the average particle diameter $\left(\mathrm{D}_{\mathrm{TEM}} 10\right.$ $\mathrm{nm}$ ) of single functionalized NPs obtained from TEM, and the density of ferric oxide $\left(4.9 \mathrm{~g} \mathrm{~cm}^{-3}\right)^{37}$, a specific surface area of $133 \mathrm{~m}^{2} \mathrm{~g}^{-1}$ is derived, which yielding a surface coverage $\Gamma$ of $17.4 \times 10^{18}$ aryl molecules. $\mathrm{m}^{-2}$. It is noteworthy that this value is close to the surface concentration of a close-packed bilayer $\Gamma_{\mathrm{CPML}}$ of phenyl (or 4-substituted phenyl) groups estimated from molecular models ${ }^{38}, \Gamma_{\mathrm{CPML}}$ $=8.1 \times 10^{18}$ aryl molecules. $\mathrm{m}^{-2}$.

After coating the NPs with PEG, the weight loss increases significantly, indicating an organic coating of up to $26 \%$ as seen in figure $5 \mathrm{c}$. 


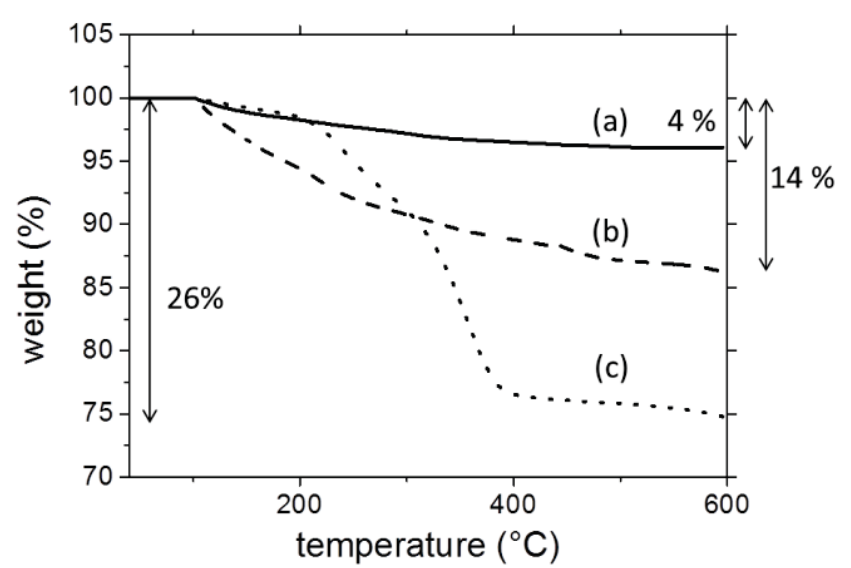

Fig. 5. Thermogravimetric analysis for the a) bare magnetite nanoparticles (full line) b) coated with amino groups (dashed line) and c) coated with PEG (dotted line).

Since the IONPs showed advantageous characteristics for biological applications, it was further imperative to evaluate their biological response ${ }^{39}$. Therefore, in order to gain insight into their potential biological effects, the compounds were tested in vitro. Using a model epithelial barrier cell-line the spherical magnetite NPs both with and without PEG coating were tested in terms of their potential cytotoxicity and (pro-)inflammatory response.

The $\mathrm{Fe}_{3} \mathrm{O}_{4} \mathrm{NPs}$ and $\mathrm{Fe}_{3} \mathrm{O}_{4}$ PEG NPs showed a concentration-dependent cytotoxic response after 24 hours exposure at particle concentrations of 0.01 to $0.08 \mathrm{mg} \cdot \mathrm{ml}^{-1} \cdot \mathrm{Fe}_{3} \mathrm{O}_{4}$ NPs showed a significant cytotoxicity $(p<0.05)$ at concentrations of 0.04 and $0.08 \mathrm{mg} . \mathrm{ml}^{-1}$, respectively, compared to cells treated with cell culture medium only. At the highest concentration of $0.08 \mathrm{mg} \cdot \mathrm{ml}^{-1}$ a significant difference $(p<0.05)$ compared to the $\mathrm{LDH}$ release caused by the $\mathrm{Fe}_{3} \mathrm{O}_{4}$ PEG NPs, at the same particle concentration, was found. No significant cytotoxicity $(p>0.05)$ was observed with $\mathrm{Fe}_{3} \mathrm{O}_{4}$ PEG NPs at any of the particle concentrations tested over 24 hour period.

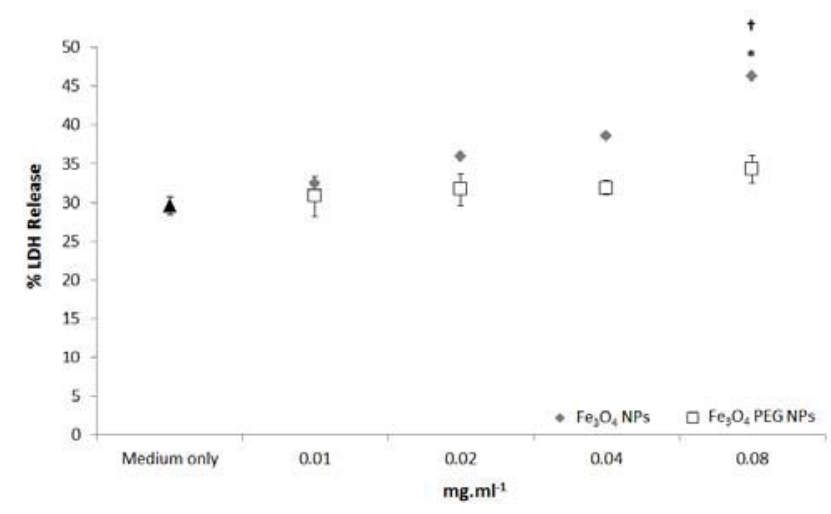

Fig. 6. \% Lactate dehydrogenase (LDH) release (as compared to the positive control $(0.2 \%$ Triton X100)) from A549 epithelial cells after exposure to $\mathrm{Fe}_{3} \mathrm{O}_{4} \mathrm{NPs}$ and $\mathrm{Fe}_{3} \mathrm{O}_{4}$ PEG NPs at 0.01, $0.02,0.04$ and $0.08 \mathrm{mg} \cdot \mathrm{ml}^{-1}$ for 24 hours at $37^{\circ} \mathrm{C}, 5 \% \mathrm{CO}_{2}(\mathrm{n}=3)$. White boxes refer to the $\mathrm{Fe}_{3} \mathrm{O}_{4} \mathrm{NPs}$, whilst grey diamonds refer to the $\mathrm{Fe}_{3} \mathrm{O}_{4}$ PEG NPs. The black triangle refers to the effects of cell culture medium only. Data presented is the mean \pm the standard error of the mean (SEM). * represent a statistical significance $(p<0.05)$ from medium only. $\dagger$ represent a statistical significance $(p<0.05)$ of the $\mathrm{Fe}_{3} \mathrm{O}_{4}$ NPs compared to the $\mathrm{Fe}_{3} \mathrm{O}_{4}$ PEG NPs at the same particle concentration.

Similar to the LDH response observed, the $\mathrm{Fe}_{3} \mathrm{O}_{4} \mathrm{NPs}$ and $\mathrm{Fe}_{3} \mathrm{O}_{4}$ PEG NPs showed a concentration-dependent response after 24 hours exposure at particle concentrations of 0.01 to $0.08 \mathrm{mg} \mathrm{ml}^{-1}$. The $\mathrm{Fe}_{3} \mathrm{O}_{4} \mathrm{NPs}$ showed a significant increase $(p<0.05)$ in IL-8 release at concentrations of 0.04 and $0.08 \mathrm{mg} \cdot \mathrm{ml}^{-1}$ compared to cells treated with cell culture medium only. The $\mathrm{Fe}_{3} \mathrm{O}_{4}$ PEG NPs were also found to elicit a significantly heightened $(p<0.05)$ IL- 8 response at particle concentrations of 0.04 and $0.08 \mathrm{mg} \cdot \mathrm{ml}^{-1}$ compared to the negative control. No significant differences $(p>0.05)$ were found between the different NP types in regards to their ability to cause a (pro-)inflammatory response in A549 cells after a 24 hour exposure period.

The biological effects observed highlight that whilst each form of IONP can elicit only a limited biochemical effect, whereas the addition of the PEG layer to the IONP surface had a beneficial additive effect upon the ability for these NPs to cause cytotoxicity and (pro-)inflammatory chemokine release response up to $0.08 \mathrm{mg} . \mathrm{ml}^{-1}$ in vitro. The findings in the present study supports the previous results reported in the literature where effects of a PEG coating on $\mathrm{NH}_{2}$ surface functionalized quantum dots (QDs) ${ }^{40}$ showed that $\mathrm{NH}_{2}$ (PEG) surface modified QDs elicited only a limited level of cytotoxicity when exposed to macrophages in vitro over $24 \mathrm{hrs}$ at an $80 \mathrm{nM}$ particle concentration. Similar findings were also reported by Zhang et al ${ }^{41}$ in which PEG-silica coated QDs were found to only elicit moderate cytotoxicity in two different cancer cell-lines up to $80 \mathrm{nM}$ particle concentrations in vitro. Such findings suggest that, independent of the NP and cell type used, PEG is able to act as a limiting factor towards any potentially adverse effects that could be elucidated by NPs ${ }^{42}$. Furthermore, in a recent study by ${ }^{43}$ Brandenberger et al., it was observed that a PEG surface coating upon gold citrate stabilized NPs caused a significant decrease upon the uptake kinetics of NPs by the same epithelial cells used in the present study. These findings further support the notion that PEG creates a 'repulsive barrier ${ }^{44}$ between a (nano)material and a biological system, enabling it to be used as an ideal biomaterial for numerous applications.

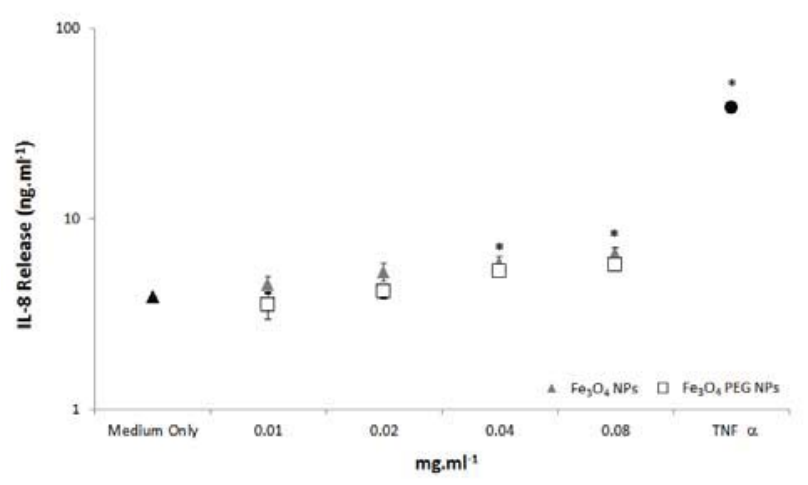


Fig. 7. Release of the (pro-)inflammatory chemokine interleukin (IL)-8 from A549 epithelial cells after exposure to $\mathrm{Fe}_{3} \mathrm{O}_{4} \mathrm{NPs}$ and $\mathrm{Fe}_{3} \mathrm{O}_{4}$ PEG NPs at $0.01,0.02,0.04$ and $0.08 \mathrm{mg} \cdot \mathrm{ml}^{-1}$ for 24 hours at $37{ }^{\circ} \mathrm{C}, 5 \% \mathrm{CO}_{2}(\mathrm{n}=3)$. White boxes refer to the $\mathrm{Fe}_{3} \mathrm{O}_{4} \mathrm{NPs}$, whilst grey diamonds refer to the $\mathrm{Fe}_{3} \mathrm{O}_{4}$ PEG NPs. The black triangle refers to the effects of cell culture medium only. The black circle refers to the effects of the positive control, tumour necrosis factor (TNF)- $\alpha$. Data presented is the mean \pm the standard error of the mean (SEM). * represent a statistical significance $(p<0.05)$ from medium only.

\section{Conclusions}

In summary, in the present study we have developed a very simple and original RT aqueous synthesis procedure yielding biocompatible individually dispersed iron oxide NPs suitable for biological applications with a covalent attachment dispersible in water by taking advantages of the aryl diazonium salt chemistry. Our approach, elicits limited biological effects in vitro, and offers several advantages over conventional methods such as a stability of the covalent link between the inorganic core and the organic coating, and the possibility to graft polymers, dyes or proteins to the surface of IONPs.

In conclusion, the afore described method offers great promise for the design of stable, magnetic nano-sized particles, but moreover that this approach will likely find many other applications for the synthesis of hybrid materials.

\section{Associated Content}

Supporting Information.

RMN Spectra of the diazonium salt $\mathrm{Cl}^{-{ }^{+}} \mathrm{N}_{2}-\mathrm{C}_{6}-\mathrm{H}_{4}-\mathrm{NH}_{2}$. FT-IR spectra of bare cubic/spindle hematites NPs, amino coating cubic/spindle hematites NPs and pegylated cubic/spindle hematite NPs. FT-IR spectra of the free diazonium salt $\mathrm{Cl}^{-{ }^{+}} \mathrm{N}_{2}-\mathrm{C}_{6}-\mathrm{H}_{4}-\mathrm{NH}_{2}$ and the coated $\mathrm{NP}-\mathrm{C}_{6} \mathrm{H}_{4}-$ $\mathrm{NH}_{2}$.

\section{Acknowledgements}

Financial support by the Adolphe Merkle Institute foundation and Swiss National Science Foundation, project 132736, is gratefully acknowledged.

\section{References}

[1] S. Balasubramaniam, N. Pothayee, Y. Lin, M. House, R.C. Woodward, T.G.St. Pierre, R.M. Davis and J. S. Riffle, Chem. Mater. 23 (2011) 3348.

[2] T. Hyeon Chem. Commun. (2003) 927.

[3] D. L. Leslie-Pelecky,R. D. Rieke, Chem. Mater. 8 (1996), 1770 .

[4] A. K. Gupta, M. Gupta, Biomaterials 26 (2005) 3995.

[5] J. M. Perez, Nature Nanotechnology 2 (2007) 535.

[6] J. Choi, Y. Jun, S. Yeon, H. Chan Kim, J. Shin and C. Jinwoo, J. Am. Chem. Soc. 128 (2006), , 15982.

[7] S. S. Banerjee, D.H. Chen Chem. Mater 19 (2007) 6345.
[8] (a) H. Mouaziz, R. Veyret, A. Theretz, F. Gino, and A. Elaissari, J. Biomed. Nanotechnol. 5, (2009), 172(b) M. Rahman, M. M. Chehimi, H. Fessi and A. Elaissari, J. Colloid Interface Sci., 360, (2011) 556.

[9] C. Boyer, M.R. Whittaker, V. Bulmus, J. Liu and T. P. Davis, NPG Asia Mater. 2 (2010) 23.

[10] H. Goesmann, C. Feldmann, Angew. Chem. Int. Ed. 49 (2010) 1362.

[11] S.M. Moghimi, A.C. Hunter, J.C. Murray, Pharmacol Rev. 53 (2001) 283.

[12] L. Wang, K. G. Neoh, E. T. Kang, B. Shuter, S.-C. Wang, Adv. Funct. Mater. 19 (2009) 2615.

[13] J. Rubio-Garcia, Y. Coppel, P. Lecante, C. Mingotaud, B Chaudret, F. Gauffre, M.L. Kahn Chem. Commun. 47 (2011) 988. [14] G. Prencipe, J. Am. Chem. Soc. 131 (2009) 4783.

[15] T. K. Jain, M. A. Morales, S. K. Sahoo, D. L. Leslie-Pelecky, and V. Labhasetwar Mol. Pharmaceutics 2 (2005) 194.

[16] J. Gao, H. Gu, and B. Xu, Acc. Chem. Res. 42 (2009) 1097.

[17] (a) Md M. Rahman, A. Elaissari, J. Colloid Sci. Biotechnol. 1 (2012) 3; (b) S.F. Medeiros, A.M. Santos, H. Fessi, A. Elaissari, J. Colloid Sci. Biotechnol. 1 (2012) 99.

[18] Z. Roveimiab, A.R. Mahdavian, E. Biazar, S.K.Heidari, J. Colloid Sci. Biotechnol. 1 (2012) 82.

[19] C.C. Berry, A.S.G. Curtis, J Phys D: Appl. Phys. 36 (2003) 198.

[20] M. Mikhaylova, D. Kyung Kim, C.C. Berry, A. Zagorodni, M. Toprak, A.S.G. Curtis and M. Muhammed Chem. Mater. 16 2344.

[21] Sahoo, Y.et al., Langmuir 17 (2001) 7907.

[22] N. Miguel-Sancho, O. Bomati-Miguel G. Colom, J.P. Salvador, M.P. Marco and J. Santamari, Chem. Mater. 23 (2011) 2795.

[23] K. Cheng, S. Peng, C. Xu, S. Sun, J. Am. Chem. Soc. 131 (2009)10637.

[24] M. D. Shultz, J. U. Reveles, S. N. Khanna, E. E. Carpenter, J. Am. Chem. Soc. 129 (2007) 2482.

[25] N. Griffete, F. Herbst, J. Pinson, S. Ammar and C. Mangeney J. Am. Chem. Soc. 133 (2011) 1646.

[26] N. Griffete, A. Lamouri, F. Herbst, N. Felidj, S. Ammar, and C. Mangeney RSC advances 2 (2012) 826.

[27] N. Griffete, A. Lamouri, S. Ammar and C. Mangeney, J. Mater. Chem. 22 (2012) 1807.

[28] (a) S. A. Dahoumane, M. N. Nguyen, A. Thorel, J. P. Boudou, M. M. Chehimi, and C. Mangeney, Langmuir 25 (2009) 9633 (b) S. Mahouche Chergui, N. Abbas, T. Matrab, M. Turmine, E. Bon Nguyen, R. Losno, J. Pinson and M. M. Chehimi Carbon 48 (2010) 2106.

[29] (a) H. Gehan, L. Fillaud, M. M. Chehimi, J. Aubard, A. Hohenau, N. Felidj, and C. Mangeney ACSNano 4 (2010) 6491; (b) F. Hauquier, T. Matrab, F. Kanoufi and Combellas, C. Electrochim. Acta 54 (2009) 5127; (c) T. Matrab, M. M. Chehimi, C. Perruchot, A. Adenier, V. Guillez, M. Save, B. Charleux, and J. Pinson, Langmuir 21 (2005) 4686.

[30] L. Andruzzi, B. Nickel, G. Schwake, J.O. Radler, K.E. Sohn, T.E. Mates E.J. Kramer, Surface Science 601 (2007) 4984.

[31] D. Brogioli, D. Salerno, V. Cassina, S. Sacanna, A.P. Philipse, F. Croccolo, and F. Mantegazza Optics Express +/ (2009) 1222.

[32] M. Ocana, M. P. Morales, and C. J. Serna, J. Colloid Interface Sci. 212 (1999) 317.

[33] (a) F. Sauzedde, F. Ganachaud, A. Elaïssari, C. Pichot, J. Appl. Polym. Sci. 65 (1997) 2331; (b) H. Mouaziz, R. Veyret, A. Theretz, F. Ginot, and A. Elaissari, J. Biomed. Nanotechnol. 5, (2009) 172.

[34] G. T. Hermanson Bioconjugate techniques, 2nd ed.; Academic Press: Amsterdam [Netherlands], Boston [Mass.], 2008.

[35] C. Rufier, M. Reufer, H. Dietsch, and P. Schurtenberger, Langmuir 27 (2011) 6622. 
[36] E. Amstad, S. Zurcher, A. Mashaghi, J.Y. Wong, M. Textor, and E. Reimhult, Small 5 (2009) 1334.

[37] The specific surface area $\left(\mathrm{S}_{\mathrm{sp}}\right)$ was calculated using $\mathrm{S}_{\mathrm{sp}}=$ $6 / \rho \mathrm{D}$ where $\rho$ is the $\mathrm{Fe}_{2} \mathrm{O}_{3}$ density and $\mathrm{D}$ is its particle diameter. Then, from the weight $\%$ of the aryl organic coating $\left(\mathrm{W}_{\text {aryl }}\right)$ and the magnetic $\mathrm{Fe}_{2} \mathrm{O}_{3}$ core $\left(\mathrm{W}_{\mathrm{Fe} 2 \mathrm{O}}\right), \Gamma$ could be computed using: $\Gamma=$ $\left(\mathrm{N}_{\mathrm{A}} \times \mathrm{W}_{\text {aryl }}\right) /\left(\mathrm{S}_{\mathrm{sp}} \times \mathrm{M} \times \mathrm{W}_{\mathrm{Fe} 2 \mathrm{O} 3}\right)$ where $\mathrm{M}$ is the molar mass of attached functional aryl groups $\left(92\right.$ g.mol ${ }^{-1}$ ) and $\mathrm{N}_{\mathrm{A}}$ is the Avogadro's number.

[38] (a) J. Pinson, and F., Podvorica, Chem. Soc. Rev. 34 (2005) 429 (b) D. Belanger, and J. Pinson, Chem. Soc. Rev. 40 (2011) 3995.

[39] U. Pison, T. Welte, M. Giersig, D. A. Groneberg, Eur. J. Pharm 533 (2006) 341.

[40] M. J. D. Clift, J. Varet, S. M. Hankin, B. Brownlee, A; Davidson, C. Brandenberger, B. Rothen-Rutishauser, D. M. Brown, and V. Stone, Nanotox 5 (2011) 664.
[41] T. Zhang, J.L. Stilwell, D. Gerion, L. Ding, O. Elboudwarej, P.A. Cooke, J.W. Gray, A.P. Alivisatos, F.F. Chen, Nano Lett. 6 (2006) 800.

[42] M. J. D. Clift, P. Gehr and B.Rothen-Rutishauser, ArchToxicol 8 (2011) 5723.

[43] C. Brandenberger, C. Muehlfeld, Z. Ali, A-G. Lenz, O. Schmid, W. J. Parak, P. Gehr, and B. Rothen-Rutishauser, Small 6, (2010) 1669.

[44] C.J.H. Porter, S.M. Moghimi, L. Illum, S.S. Davis, FEBS Letters 305 (1992) 62. 